\title{
Electrode Erosion Observed in Electrohydraulic Discharges Used in Pulsed Sheet Metal Forming
}

\author{
John J.F. Bonnen, Sergey F. Golovashchenko, Scott A. Dawson, and Alexander V. Mamutov
}

\author{
(Submitted February 18, 2013; in revised form June 29, 2013; published online September 28, 2013)
}

\begin{abstract}
In this paper, we present results of electrode durability testing and electrode design in a pulsed electrohydraulic discharge environment. Pulsed electrohydraulic forming (EHF) is an electrodynamic process based upon high-voltage discharge of capacitors between two electrodes positioned in a fluid-filled chamber. EHF enables a more uniform distribution of strains, widens the formability window, and reduces elastic springback in the final part when compared to traditional sheet metal stamping. This extended formability allows the fabrication of panels of alternative high strength alloys that are otherwise difficult to make conventionally. It was found that, of the materials tested, steel electrodes not only survived the stresses encountered in the EHF chamber but also had lower erosion rates compared to molybdenum. Erosion rates were found to be constant for low carbon steel at $3.7 \mathrm{~mm}^{3} /$ discharge, and they were high enough that the initial tip geometry was rapidly worn away and a more geometrically and thus electrically stable tip geometry had to be selected. Entrained air in the system had little influence on erosion rates but numerical modeling suggests that the erosion process takes place during the very initial stages of the pulse. Lastly, it was determined that the electrodes discussed in this paper can survive 2000 pulses.
\end{abstract}

Keywords durability, electrode, erosion, electrohydraulic forming, forming, hydroforming, high strength alloy, impulse forming, metal forming, process development, pulse forming, stamping

\section{Introduction}

As energy costs and regulatory pressures increase on the automotive industry, and advanced high strength alloys of steel, aluminum, and magnesium are being increasingly used to achieve lightweight automotive body construction. Unfortunately, formability levels offered by these materials do not match those of the mild, bake-hardenable, and HSLA steels that constitute the great majority of current car body construction. Further development of sheet metal forming technologies is necessary to supplant the older heavier body construction materials in the automotive industry. Hydromechanical drawing (hydroforming) offers deeper drawing and more uniform distribution of strains due to substantial frictional reductions, but lacks the ability to extend the formability envelope or contend with the increased springback problems that come with high strength alloys. Electrohydraulic forming (EHF), which is similar to explosive forming, provides these capabilities and has proven able to deep form very high strength low ductility

John J.F. Bonnen and Scott A. Dawson, Ford Motor Company-Manufacturing Research, P.O. Box 2053, Dearborn, MI 48121-2053; F. Golovashchenko, Ford Research \& Advanced Engineering-Manufacturing \& Processes, Research and Innovation Center, MD3135, 2101 Village Rd., Dearborn, MI 48121; and Alexander V. Mamutov, Department of Mechanical Engineering, Oakland University, Pontiac, MI. Contact e-mail: jbonnen@ford.com.

alloys such as DP980 steel and 6061 aluminum (Ref 1) into complex shapes.

In EHF a significant amount of stored electrical energy (10$100 \mathrm{~kJ})$ is discharged across an electrode gap in a water-filled chamber. The brief, intense discharge $(<100 \mu \mathrm{s})$ causes a plasma channel to form between the electrodes which subsequently vaporizes a small volume of liquid. This very rapid plasma/steam channel formation causes a high intensity/high velocity shock wave to propagate through the liquid and toward the sheet metal blank driving it into a die clamped to the chamber. Since the liquid transmits the force, only a die (no punch) is required. Compared to electromagnetic forming (EMF) processes, EHF is applicable to wider variety of sheet metals without any special conductivity or working distance constraints. EHF can employ a single tool as multiple pulses may be used to form the part as opposed to EMF in which several different sets of coils and dies are often necessary (Ref 2).

The project objective is to develop EHF technology to the point where it is suitable for high volume production, enabling critical weight savings and improving fuel economy for cars and trucks. Critical to the implementation of this technology is the need to establish the benefits of EHF, to demonstrate the ability to reliably and robustly create discharges in the chamber, to form otherwise unformable parts with reduced springback and lastly to establish the necessary predictive tools to properly design parts and tooling.

Initial development of EHF technology began in Russia in the early 1950 s by Yutkin (Ref 3 ). Bruno (Ref 4) provided the first western overview of the technology, and Davies and Austin (Ref 5) reviewed early applications and research results on EHF. In its early development the greatest effort was dedicated to forming low volume parts at low cost. Bruno (Ref 4) described a number of industrial examples where EHF machines storing anywhere from 36 to $172 \mathrm{~kJ}$ were employed. However, due to the necessity to fill the chamber with liquid at the beginning of 
each forming cycle and empty it at the end, cycle times for EHF have traditionally been in the range of several minutes.

More recently, Balanethiram and Daehn (Ref 1) reported an increase of a factor 4 to 5 in the forming limit for AA6061 over conventional techniques when EHF forming into a conical die, and Golovashchenko and Mamutov (Ref 6) reported forming limit improvements for DP590, DP780, and DP980 of roughly a factor of 2 over conventional stamping when EHF forming into conical and plane-strain dies.

Very limited attempts have been made to simulate the EHF process. Golovashchenko and Mamutov (Ref 6) presented simulation results of bulging into an open round die. Similarly, Vohnout et al. (Ref 7) reported results of pulsed loading in a closed volume, assuming energy equivalence to explosive forming. Additional work fully modeling the discharge, pressure transmission and the part formation into the die has been done by Ford researchers (Ref 8, 9).

Of its major systems, the electrodes are the heart of the EHF process and must endure the harshest treatment. They must deliver up to $100 \mathrm{kA}$ safely into and out of the chamber, insulate the chamber from potentials up to $15 \mathrm{kV}$, and withstand the high energy densities, temperatures, and pressures generated by the discharge. They must maintain a water tight seal, be adjustable to keep the inter-electrode gap consistent, and resist the forces resulting from large pressures that attempt to either eject them from the chamber or bend them. They must be able to either withstand or accommodate the erosion caused by the electrical discharge and the high pressures generated in the chamber. Lastly, in order for EHF to be an economically viable production process, the electrode system must last for at least a single production shift, be adjustable to maintain overall system discharge performance, and be easily serviceable.

The only extant research in the literature on studying the efficiency of different electrode profiles in electrohydraulic discharges was performed by Loske and Prieto (Ref 10) in use for lithotripters. Similarly, only a small amount of work exists in the literature examining the erosion effects on electrodes of electrohydraulic discharges. Potocký et al. (Ref 11) looked at erosion on needle electrodes. Bonnen et al. (Ref 9) is the only study dedicated to electrode erosion under the large energies used in electrohydraulic forming discharge conditions. There are, however, somewhat more studies available on air or vacuum spark gap arcs, and Donaldson et al. (Ref 12) was able to determine that the decrease in damage with increasing interelectrode gap was primarily due to a molten vapor jet mechanism. Later Donaldson et al. (Ref 13) went on to directly tie electrode erosion to the charge transferred between the electrodes. In these studies stainless steel or tungsten-copper was often found to be the best electrode material with the lowest mass loss rate. Mass loss is a convenient measure, but electrode system geometry changes, especially the inter-electrode gap, are driven by volumetric changes.

The goal of this work is to identify the optimal combination of electrode materials and tip geometries that are best suited to help scale EHF into mass production.

\section{Electrohydraulic Forming Methodology}

A schematic illustration of an EHF system is shown in Fig. 1. The water-filled chamber at bottom has a pair of electrodes inserted into the chamber cavity. On top of the chamber rests a sheet metal blank, and on top of that rests the female die with the desired part shape. In order to control material flow into the die, the tool often includes a binder used to help locate the blank in the tool. A critical part of the tool design is the seals between the chamber/binder and the blank which are required to keep the liquid within the chamber. Another set of seals is located between the die and the blank - necessary to allow evacuation of the cavity between the die and blank. The entire assembly is clamped in a press.

A pulsed current generator is attached to the electrodes and the chamber itself is connected to a system that provides water, air pressure, and vacuum. A hydraulic press is used to clamp the tool in place, and an automation unit is used to deliver blanks into the tool and remove parts after forming.

Before the cycle is started, the liquid is brought to a level just below the chamber top to minimize both the likelihood of spillage and the liquid volume which is moved in and out of the EHF chamber. The automation then places a blank on the chamber and the press closes and clamps the die and chamber together. Water fills the chamber and vents are provided near the parting line to help minimize air within the system. A vacuum is placed on the vent holes in order to assist the chamber filling operation and minimize air pockets since air in the system is a source of considerable loss of efficiency. The cavity between the die and blank is then evacuated since air here acts as a barrier to final corner-filling operations.

At this point, the water pressure in the chamber may be increased to an extent sufficient to deform the blank partially into the die cavity. This pre-forming operation reduces the overall number of discharges necessary to fully form the part and potentially reduces overall cycle time, but the pressure must be relieved because excess water pressure suppresses plasma channel formation (Ref 14). Optionally, a static hydroforming unit may be used to perform the blank further.

The deformation process begins once the output of the dc high-voltage pulse generator $(5-15 \mathrm{kV})$ is placed on the electrodes. The voltage sits on the electrodes while a lightning-like conduction channel develops between the electrode tips. Once formed, current begins to flow, and a plasma channel rapidly develops between the tips. The plasma is a very low conductivity ionized gaseous channel between the electrodes that conducts large currents $(50-100 \mathrm{kA})$. The high energy density causes the plasma to rapidly expand, converting liquid water to high pressure steam, and causing a shockwave to propagate into the liquid and away from the electrodes.

The shockwave drives the water into the blank, and the blank accelerates toward the die surface. Since large blank velocities can cause the blank to rebound off of the die surface with resulting die damage and possible rupture of the blank, multiple discharges are typically used to form the part to approach the die surface incrementally. Once the blank has deflected, water is allowed to refill the chamber. This chamber back-fill after each pulse eliminates the extra volume occupied by a pocket of low pressure air and water vapor formed after the pulse. Otherwise this air pocket, which is compressed/heated during each subsequent pulse, substantially reduces the amplitude of subsequent shock waves delivered to the blank. This incremental volume of water is carefully measured in order to monitor part deformation.

Subsequent pulses/discharges require monotonically increasing energy levels, and the energy/pressure of each 
forming pulse is controlled by adjusting the maximum charging voltage applied to the capacitors. The final energy level is normally dictated by the part details (corner-filling operations require the highest energy levels/pressures), the shape of the chamber, and the blank material.

The injected volume of water decreases with each subsequent pulse decreasing to zero when the part is fully formed. The total volume of water used to fill the chamber between discharges is used to determine whether the part has been fully formed. Once formed, water is drained back down to the initial level, the press opened, and the part removed.

Ford has used EHF technology to successfully draw the partial full scale part shown in Fig. 2. The part pictured is a license plate pocket from a production decklid that, when stamped conventionally out of extra deep drawing quality steel, had a high enough scrap rate due to splits formed in the corners that it made the part quite marginal from a business perspective. Ford Research took the portion of the design where splitting occurred, placed lock beads around the perimeter to prevent in-flow of material in order to reproduce the constraint offered by the full panel, and proceeded to make parts from a number of steels with a wide range of yield strengths and elongations. Figure $2 \mathrm{a}$ shows the full partial panel formed out of BH180 steel, and Fig. 2b shows the panel successfully formed from the hardest to form exterior body sheet steel, DP500. These materials both required five discharges of increasing intensity to fully form the details at the bottom of the draw.

\section{Electrode System Failure Modes}

In EHF, the large currents carried by the electrodes, the erosive high temperature plasma and, lastly, as determined by Chachin, the extreme pressures acting at the electrode tips (2$3 \mathrm{GPa}$ ) (Ref 15) all act to shorten the electrode life in a variety of ways. An early chamber design is shown in Fig. 3, and the conductor failure modes, in order of increasing severity, are shown in Fig. 4. The first failure type, asymmetric erosion, is a result of the electrode orientation in the chamber design of Fig. 3 and the pressure wave emanating from the interelectrode gap. The second failure type, observed in Fig. 4(b), can also be tied to the chamber design/electrode orientation, but can also happen because of reflected pressure waves and lack of lateral electrode support. Most electrodes fail as a result of the last failure mode, erosion, shown in Fig. 4(c), and subject of this paper. Plasma arc erosion is largely responsible for increasing inter-electrode gaps such that a functional system failure occurs - a faulty discharge or no discharge at all.

\section{Electrode Testing Program}

A program was developed to investigate electrode erosion performance and improve it sufficiently so that EHF can be used in a production environment. The factors that influence electrode performance are material, tip shape, and discharge

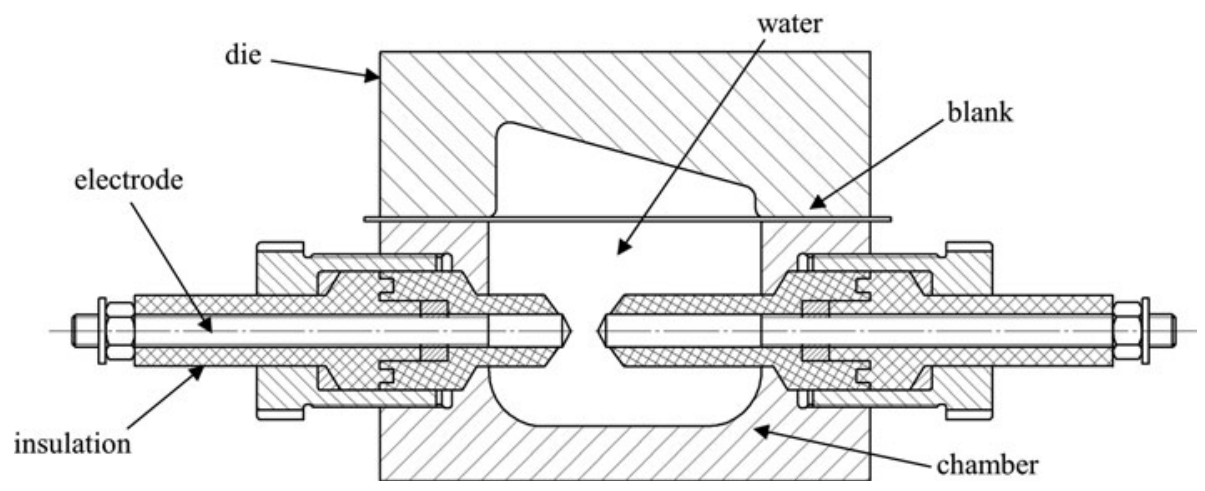

Fig. 1 Design of the electrohydraulic forming tool: chamber/tool cross section
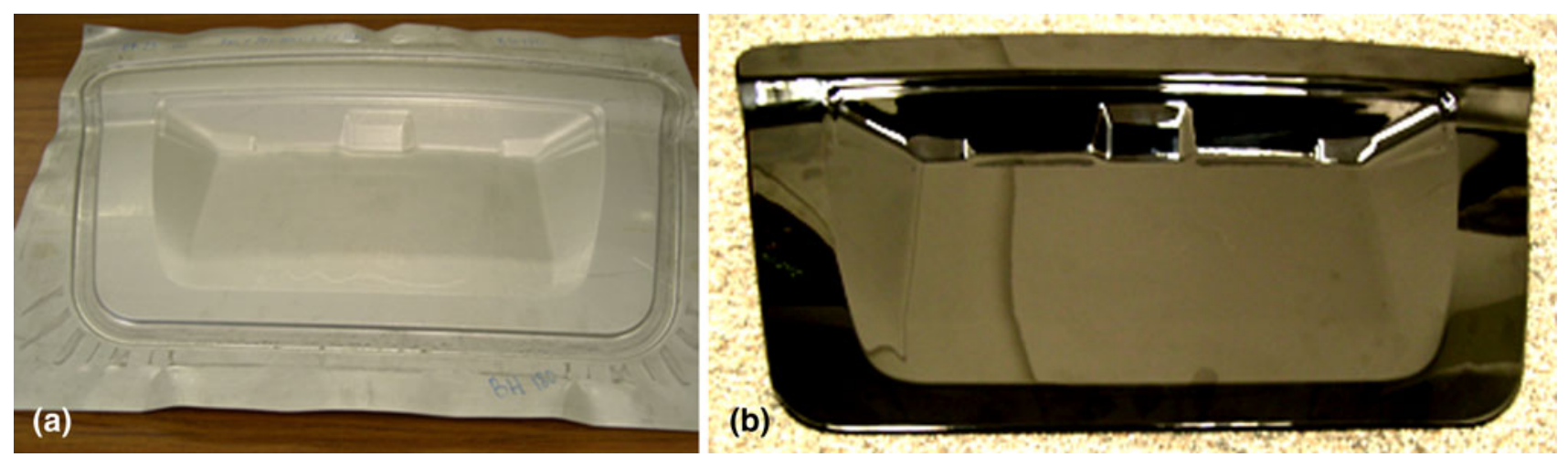

Fig. 2 License plate pocket panel formed from (a) BH210 and (b) DP500 steels 
energy. A dedicated chamber was developed with which to perform accelerated testing and, as shown in Fig. 5, the volume of the liquid in the chamber was quite small, roughly one-tenth the volume of a chamber used for producing a modest-sized automotive panel. In this chamber, instead of a sheet metal blank and die, a thick steel plate was used to seal the chamber. Reducing the volume of the chamber and eliminating the sheet metal blank significantly increases the pressure levels and promotes faster accumulation of electrode damage. Thus this smaller and much more highly constrained volume significantly increases the pressures and forces in the chamber and

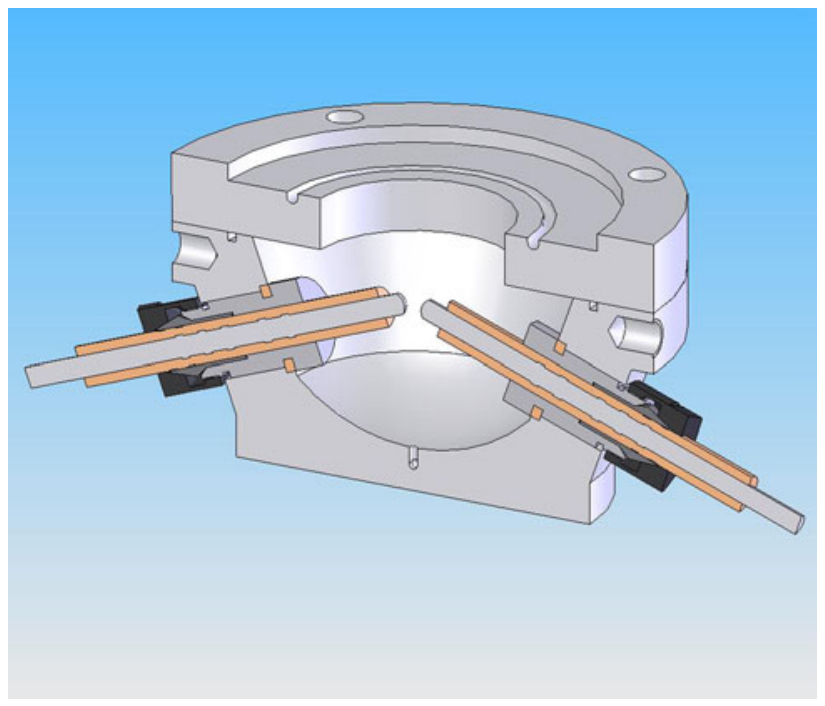

Fig. 3 Early electrode system design accelerates the durability component of the test. In the design, directly opposed electrodes were used to (mostly) eliminate the bending failure mode observed in Fig. 4(b).

All tests employed a consistent $11 \mathrm{kV}(12.1 \mathrm{~kJ})$ pulse, selected to be an above-average energy level used in automotive panel forming. In erosion testing 120 pulses were consistently discharged through each pair of electrodes (where possible) before test termination, and periodically the chamber was opened and the electrodes were inspected for damage. Throughout testing the current and voltage performance of the electrodes were monitored and recorded. At the end of the test the total electrode erosion and damage were documented.

Two pulse generators were used in this work. The primary unit was a $22.5 \mathrm{~kJ} / 15 \mathrm{kV} / 200 \mu \mathrm{F}$ pulse generator capable of $100 \mathrm{kA}$ peak current. The secondary unit, used for the high durability test, was a $100 \mathrm{~kJ} / 25 \mathrm{kV} / 320 \mu \mathrm{F}$ capable of $1.6 \mathrm{MA}$ peak current. This latter unit was reconfigured to $62.5 \mathrm{~kJ} /$ $25 \mathrm{kV} / 200 \mu \mathrm{F}$ to deliver the equivalent energy/voltage to the testing chamber as the first pulse generator, and this second quick fire unit was only used in a single test in order to more quickly determine the maximum number of discharges that an electrode pair could survive. By maintaining energy and voltage equivalence it is expected that the amount of damage done to the electrodes is equivalent.

A series of different studies were conducted to examine the following effects: erosion in different electrode materials, the effect of different tip geometries, and the effect of entrained air in the chamber on the erosion rate-all were tested using the electrode testing chamber. A final test was performed where the inter-electrode gap was varied and the effect on the EHF system performance was studied.

The electrode materials study examined several different materials for their suitability for use in an EHF chamber. It was
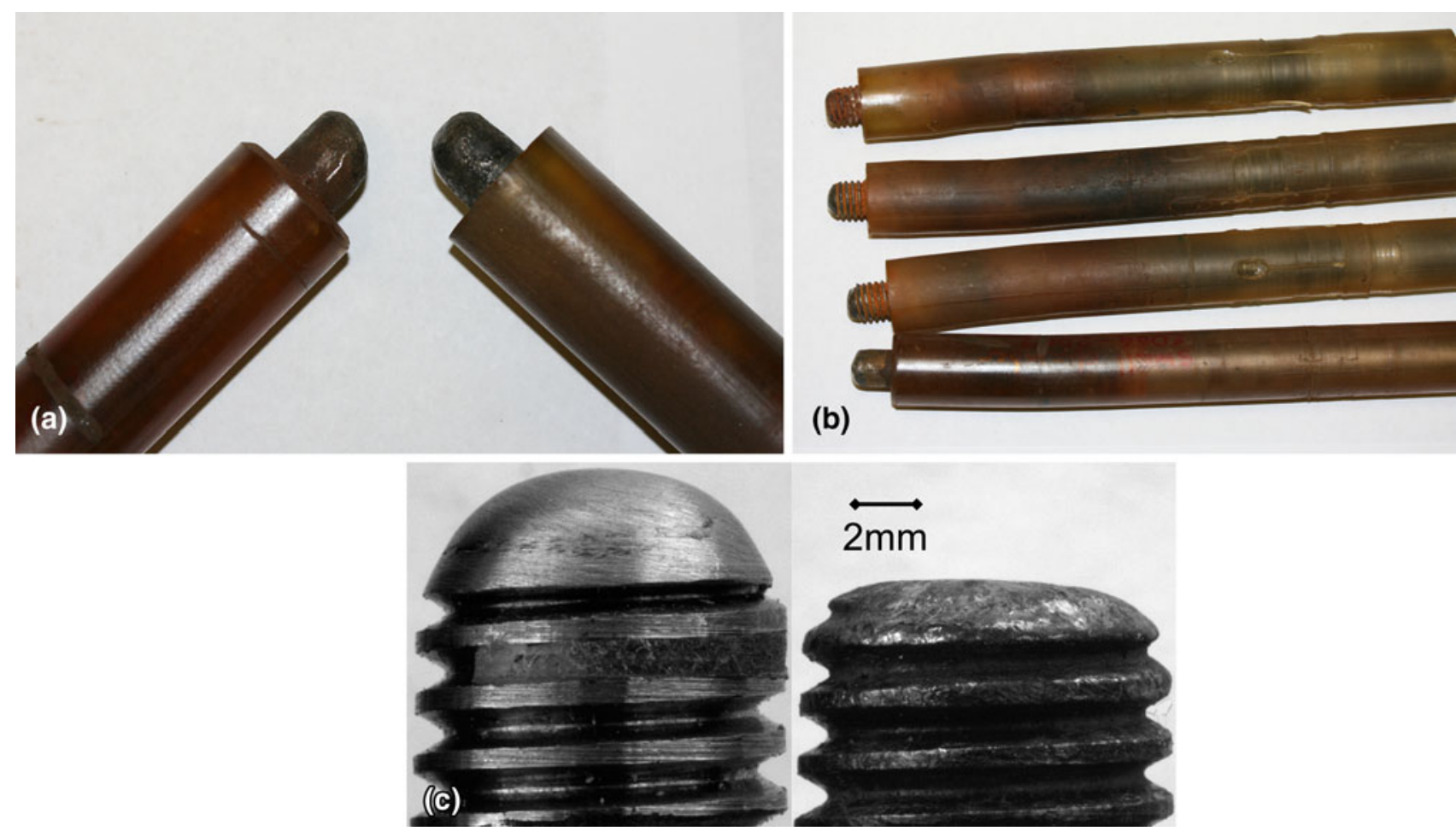

Fig. 4 Electrode failure modes: (a) asymmetric erosion; (b) bending; and (c) erosion: before and after 120 pulses 
believed that the refractory metals might offer the best performance because of their high melting point. M-184 tungsten alloy, commercially pure molybdenum, a tungsten-copper powder metallurgy alloy used for spot welding electrodes, and a plain carbon cold rolled steel (SAE 1018) were studied.

The tip geometries examined were conical, hemispherical, and flat. The opposing electrode was always of the same configuration. Lastly, the effect of entrained air was studied using an electrode testing chamber with a special top that caused the experiment to maintain a consistent air volume. These last series of experiments were performed to understand whether cavitation, which would increase with increased air volume, would unduly affect the electrode life.

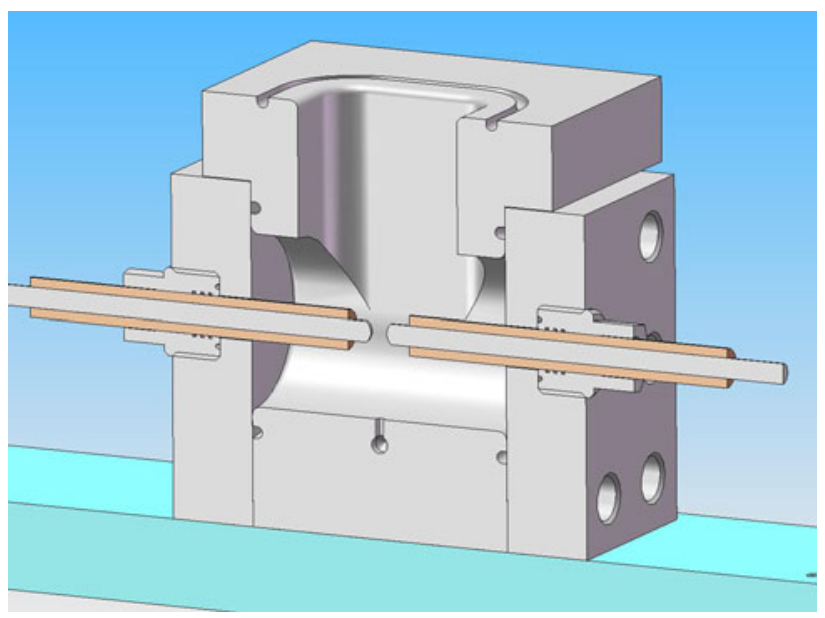

Fig. 5 Cross section of $1.8 \mathrm{~L}$ electrode testing chamber. A thick steel plate covers the top during testing. Not shown are the braces which anchor the electrode ends to the G-10 base plate and prevent electrode ejection
Figure 6 shows the electrodes that were used in the studies. Two variants of this design were used-one in which the insulation was interlocked with the electrode metal via a series of lands and another in which the interlock was achieved through a thread in the metal. The former is shown in the figure and was used in early experiments, especially in experiments with refractory metals, but the threaded design was used later and in the majority of experiments. Electrode tip shapes were simply cut into the electrode ends: hemispherical as shown, a flat tip was a simple right circular cylinder, and conical tips were right circular cones with an angle of $33.6^{\circ}$ measured against the electrode axis. The electrodes had a $12 \mathrm{~mm}$ diameter.

A typical EHF discharge electrical characteristic is shown in Fig. 7. The pulse generator applies the charge voltage $\left(V_{\text {charge }}\right)$ for roughly $1 \mathrm{~ms}$ before the formation of the plasma channel (at $t=0)$. The initial peak observed at the tool, indicated by $V_{\max }$ and delineated by the box drawn in Fig. 7 (also see inset figure), is not observed at the pulse generator capacitors but has been noted by other researchers (Ref 10). During this time there is a leak down of the voltage so that, at the moment of discharge, the voltage ( $\left.V_{\text {discharge }}\right)$ has dropped somewhat. This drop arises from leakage through the liquid medium between the exposed metal surfaces of the electrodes. Experiments with electrodes that had a significantly larger electrode surface area have shown that the leakdown rate varies directly with the exposed electrode area. After $V_{\text {discharge }}$ the plasma channel forms, current begins to flow, and the voltage rapidly drops to zero by the time the peak current is achieved. It is during this initial $30 \mu$ s period that most of the energy is delivered into the plasma channel and the pressure pulse is generated. The tail on the pulse is an indication of how long the plasma channel remains active before collapse.

Electrical performance was recorded throughout the experiments and was used predominantly to determine whether discharges were either good or faulty.
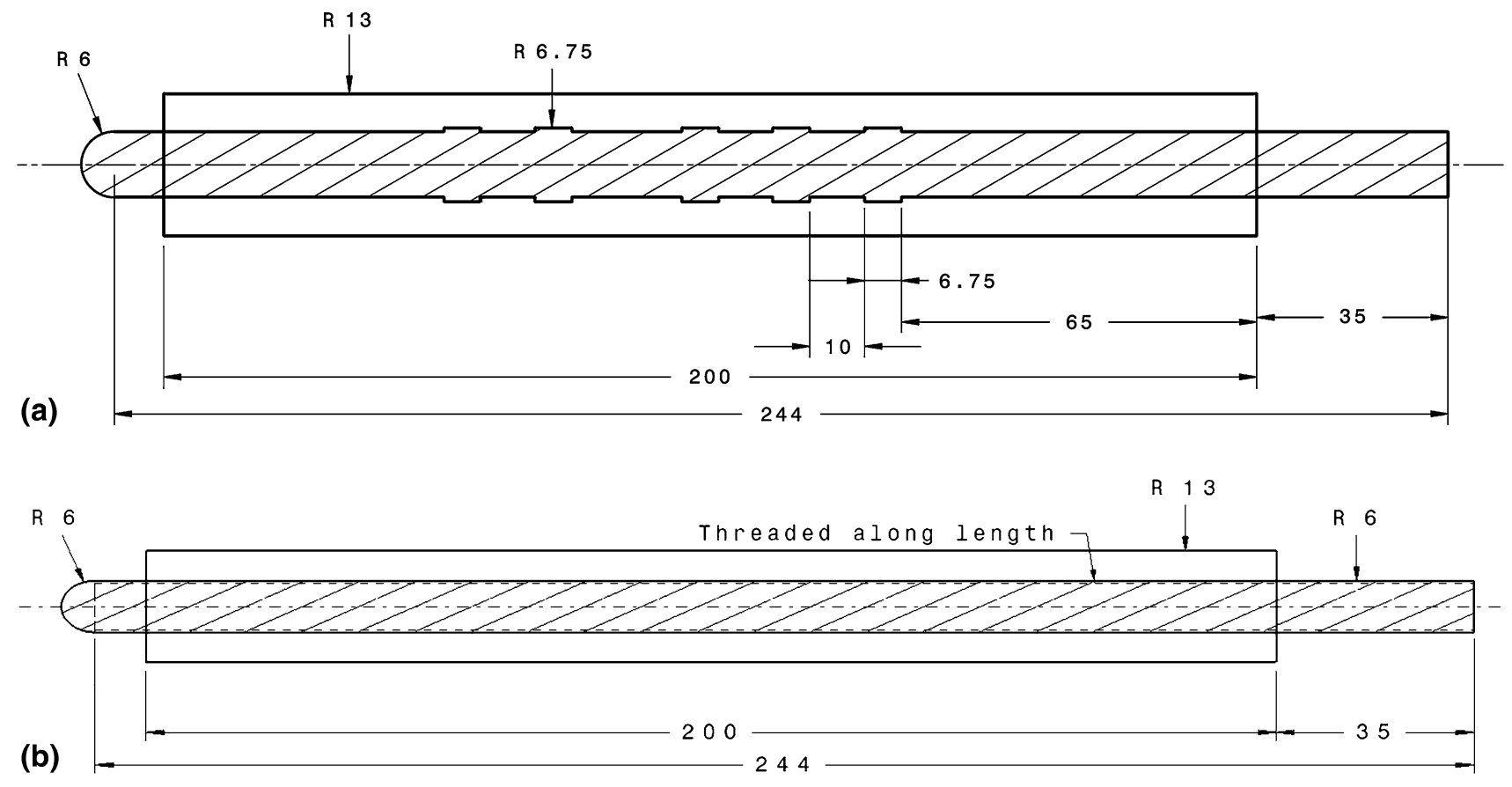

Fig. 6 Electrode designs: (a) old and (b) threaded (all dimensions in mm) 
Electrode length loss through erosion was determined through a specially developed fixture that could track electrode length changes to an accuracy of $0.01 \mathrm{~mm}$. This same fixture was used with a macro camera to document geometrical changes throughout the test with calibrated photographs. When

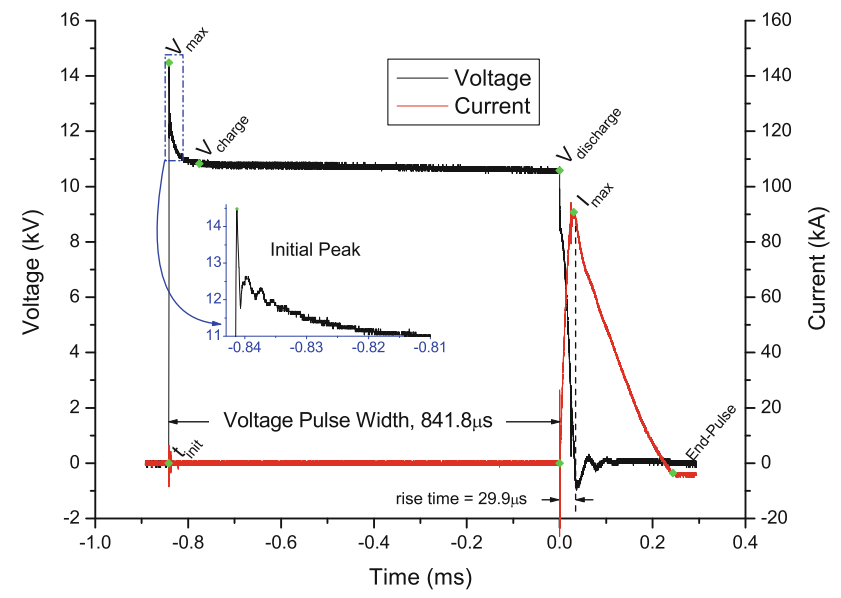

Fig. 7 Typical $11 \mathrm{kV}(12.1 \mathrm{~kJ})$ electrical pulse showing initiation of the plasma channel at $t=0$ it was determined that the volume lost was the critical parameter, these length measurements were combined with initial and final geometries derived from the macrographs to determine the total volume lost at the end of the test.

\section{Results of Electrode Testing}

\subsection{Electrode Materials Tests}

Electrode tests were conducted on SAE 1018 cold rolled steel, molybdenum, M-184 tungsten, and a copper-tungsten powder metallurgy alloy. The electrodes were constructed with hemispherical tips and tested in the chamber for up to 120 good discharges. Of these materials, only the steel survived the full 120 discharges. Molybdenum survived 15 discharges before the negative electrode fractured in a brittle fashion outside the chamber at the pulse generator attachment point (Fig. 8b), likely as a result of the combination of residual stresses, a notch and the forces from the discharge. There was some evidence of plasma arcing across the crack-faces observed in the second failure (Fig. 8c). The electrode broke two more times in a similar fashion after similar intervals, and the test was finally suspended-this behavior suggests somewhat stable crack
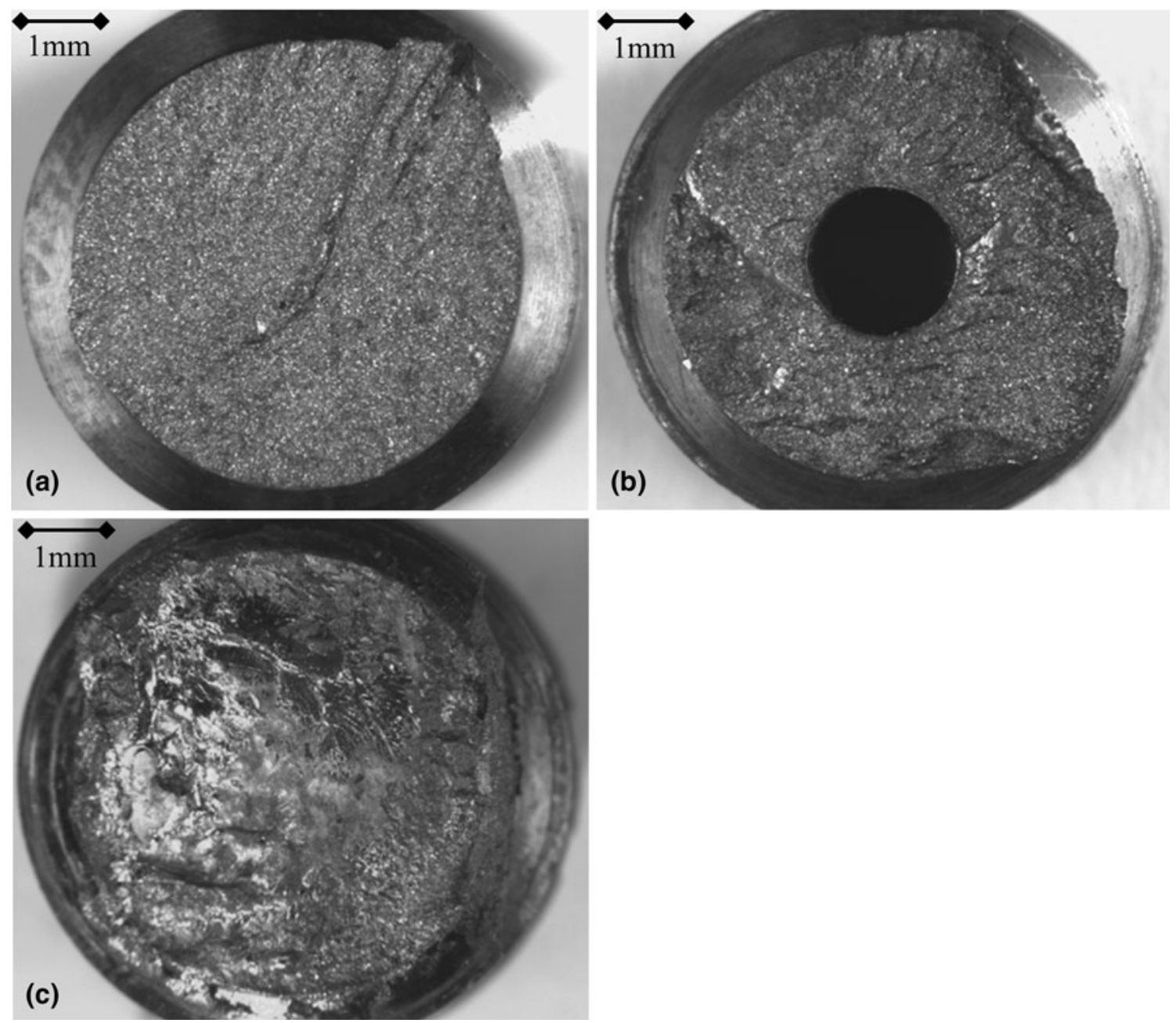

Fig. 8 Brittle failures in the threaded region of the electrode external to the EHF chamber: (a) tungsten failure and (b) first molybdenum failure at end of turned machining center and (c) second Mo failure showing fracture surface melting 
propagation. The tungsten negative electrode broke in a similar fashion but after only a single discharge and the test was suspended. The tungsten-copper PM material broke inside the chamber under the insulation due to the bending forces after roughly 70 discharges. Volumetric erosion measurements were conducted on the first three materials shown in Fig. 9. Because of uncertainty as to when the tungsten-copper electrodes fractured, the erosion rates for these electrodes were not reported in Fig. 9 or subsequent figures. The results of Fig. 9 indicate that the molybdenum showed significantly poorer erosion performance while the tungsten did not have enough discharges on it to be measured. The prohibitive material and machining costs associated with these refractory metals and their poor performance makes steel the clear choice.

In addition to the total loss rates that were examined, the individual loss rates on both the ground (cathode) and energized electrodes (anodes) were recorded, and they are indicated by the +45 and the -45 hatching in Fig. 9, respectively. In this and subsequent experiments the results consistently show the energized electrode (anode) loses nearly twice the volume of material when compared to the ground electrode (cathode).

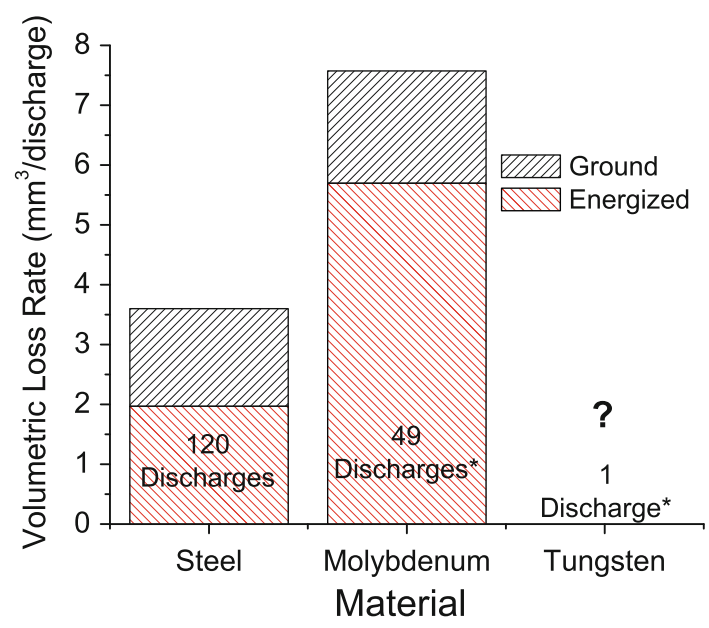

Fig. 9 Volumetric erosion rate per discharge for electrode materials. Tungsten erosion after a single discharge was not measureable

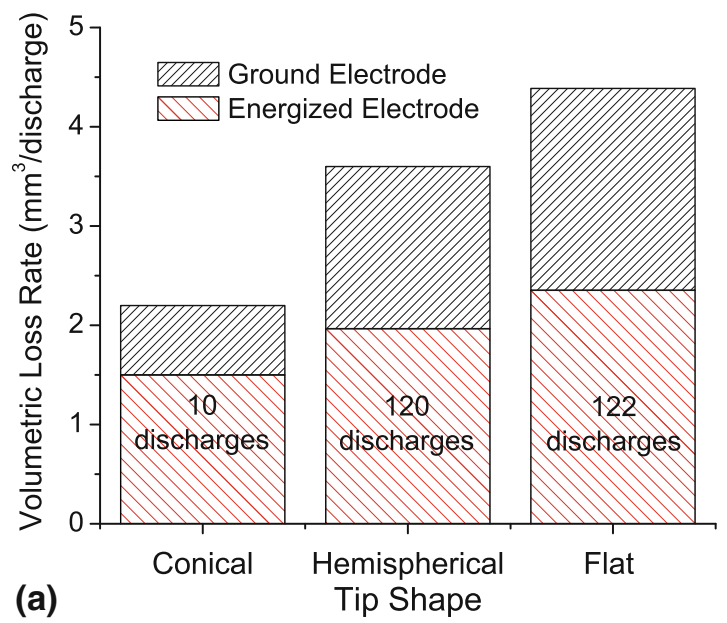

There are no extant examples of researchers observing electrode erosion using a unipolar pulse in an electrohydraulic discharge_-Loske and Prieto (Ref 10), and Potocký et al. (Ref 11) both use bipolar discharges and do not separate erosion results for the two electrodes, probably because of similar erosion. It is well documented in the literature on air-gap discharges (Ref 12, 13) that greater erosion occurs in the cathodes under unipolar discharges while bipolar discharges lead to similar erosion losses in both electrodes. A detailed discussion of the effects of material removal from the anode during pulsed discharges in water can be found in Ref 17, and a number of factors may be at play. In the article the authors use the term pulsed electrolyzation to describe the material removal. A complex phenomenon, electrolyzation usually requires much longer time intervals than that found in a pulsed EHF discharge, yet the transient effects described in Ref 17 seems to be applicable to the material loss from the anode - the combination of short time scale as well as very high amplitude pulsed loads means that material deposition cannot take place. Further, in the area where the initial plasma channel contacts the electrode, local melting is expected (Ref 15), and electrolyzation promotes faster removal of the material from the anode even though melting takes place on the surface of both electrodes. Lastly, since the anode is exposed longer to high potential during initial stage of the channel formation, more material may be lost on the anode during pulsed ionization breakdown of water (Ref 18). Ultimately, more research is necessary to understand the underlying mechanisms behind the greater material losses observed for anodes.

\subsection{Electrode Tip Shape Tests}

A series of tests was conducted to determine optimum tip shape amongst the three selected: hemispherical, conical, and flat. Initially the study was to focus on the efficiency of discharge/plasma formation and the optimal tip configuration (and combination) to achieve that goal. The electrode profile or tip shape can significantly influence the electrostatic fields set up after the voltage is applied to the electrodes and affects plasma channel formation and timing. The inter-electrode gap also influences these processes. Unfortunately, applying a modest numbers of discharges to the conical tip electrode pair results in rapid loss of electrode length through erosion and the

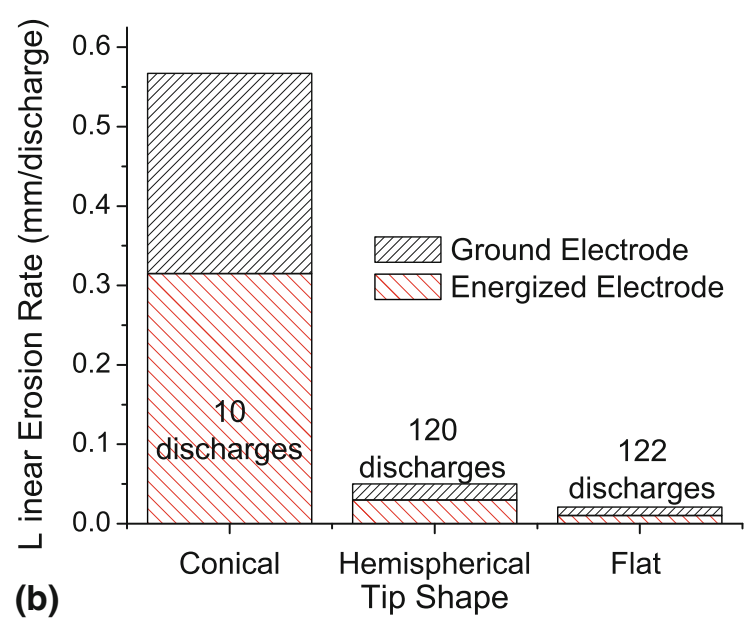

Fig. 10 Linear and volumetric erosion rates of steel electrodes with different initial tip shapes. The graph at (a) shows the volumetric loss rate and (b) shows the data plotted against lost electrode length 
subsequent increase in inter-electrode gap became the dominant concern.

Steel was used as the electrode material for these tests, and Fig. 10(a) shows a bar graph indicating the volumetric loss rate for each of the tip shapes. It is believed that the volume lost is roughly constant regardless of the tip shape as suggested by Donaldson et.al. (Ref 12). For similarly configured electrode system tests (same tip/material/chamber), the nominal erosion rate for both electrodes combined for steel is about $3.7 \pm 0.5 \mathrm{~mm}^{3} /$ discharge for tests with 120 discharges, and the

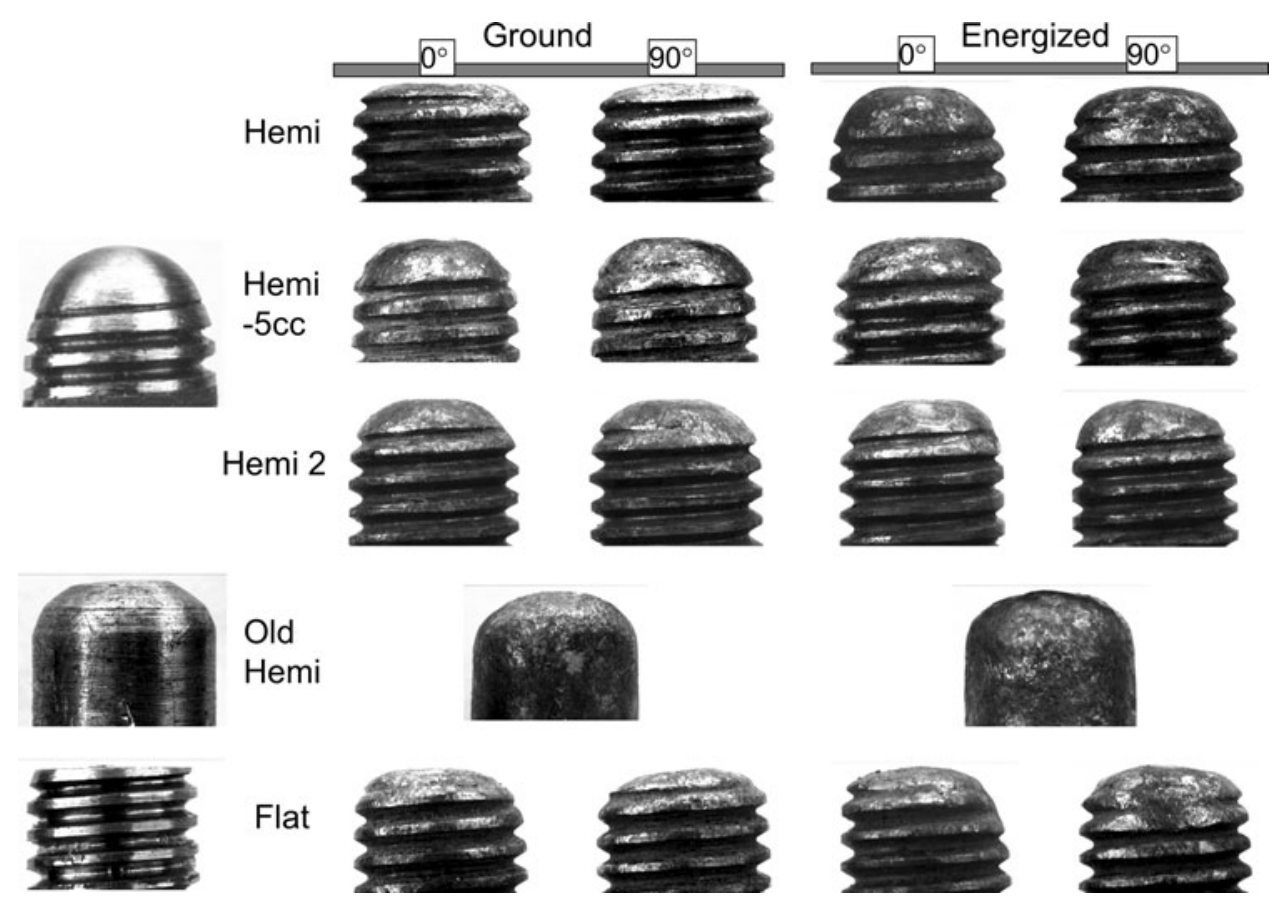

Fig. 11 Initial and final electrode profiles after 120 pulses. With the exception of the "Old Hemi" electrode design from Fig. 6a, each electrode is pictured in two orientations $\left(0^{\circ}\right.$ and $\left.90^{\circ}\right)$
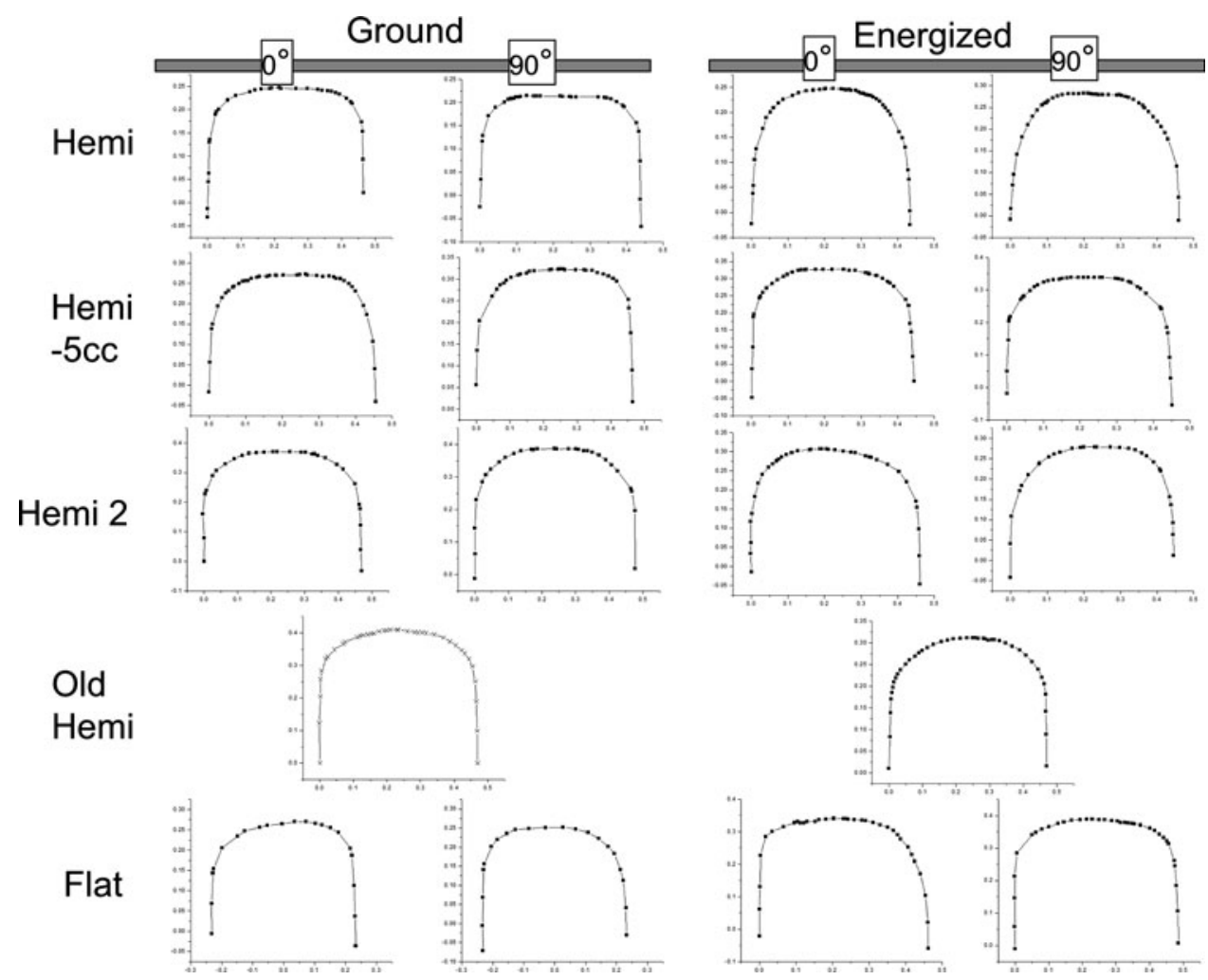

Fig. 12 Digitized final electrode profiles after 120 discharges 
hemispherical and flat electrode tests fall within reasonable bounds of this number. The stability of this number across a wide variety of tests suggests that the erosion process is not dependent on first-order geometry. Testing on the conical electrodes had to be terminated early after only 10 discharges because the gap increase was too severe, and this relatively small number of discharges resulted in a low value of erosion with a high error. Figure 10(b) shows the average electrode length loss rates for each electrode geometry. After only 10 discharges the pulses on the conical electrodes, enough linear electrode length had been lost by both electrodes that the gap increased to the point where discharges became unstable and eventually could not be produced. The implication of this result is that geometric tip stability under erosion has greater impact on process stability than the electrical efficiency of the initial tip shape.

Further, after considerable testing it was noticed that, regardless of the starting shape, orientation, or function, the electrodes eventually all assumed a similar profile - as can be seen in Fig. 11 - and this stable profile was achieved roughly half way through the required 120 discharges. Initially it was thought that the electrodes would hold their shape because the erosion was not that significant, but this was found to be incorrect. A stable profile would therefore provide the greatest overall process electrical stability and, thus the image profiles of Fig. 11 were digitized, and the result is shown in Fig. 12. The digital profiles were then normalized against the electrode radius, and the data analyzed in a number of different ways.

In order to produce the profiles in Fig. 12 the photographic profile was digitized, taking care to capture the profile only at the tips of the threads along the sides. The profile centerline was found, the data was split into right and left halves, the right half data reflected onto the left side, the two halves averaged into a single profile, and the highest $y$-value on the averaged profile was set to zero. This same procedure was then performed on the $90^{\circ}$ orientation, and that result was then averaged with the $0^{\circ}$ result. The electrode profiles were collected for the energized electrodes alone, averaged together, and the result is plotted in Fig. 13a. The same process was repeated on the ground electrodes, and then, finally, the ground and energized profiles were averaged together to yield the "average" profile. Shown along with these profiles in Fig. 13a are the minimum and maximum profiles which are an accumulation of the lowest and highest points from the raw profile data. Within the limited dataset, the maximum and minimum profiles establish a rough envelope of as-eroded profile shapes. The differences between the ground, energized, and average profiles is relatively minor.

Because the volume loss is greatest on the energized electrode, its average profile was selected for further study. An equation of the form $y(x)=-\left(y_{o}+A_{1} e^{(x-1) / t_{1}}+A_{2} e^{(x-1) / t_{2}}+\right.$ $\left.A_{3} e^{(x-1) / t_{3}}\right)$ was fit to the profile, where $x(0 \leq x \leq 1)$ is the radial displacement from the electrode centerline normalized against the radius $\left(r / r_{\mathrm{o}}\right)$ and $y$ is the distance along the electrode's length also normalized against the radius - the origin is at the tip of the electrode at the centerline, as presented in Fig. 13. The resulting parameters from the curve fit are presented in Table 1, and the results can be seen in Fig. 13(b).

A set of electrodes was fabricated with the best fit tip profile. They were tested and the averaged tip profile results are shown in Fig. 13(b) in comparison with the average energized and ground data. The averaged energized natural tip data falls above but reasonably close to the best fit line. The averaged natural tip ground data falls reasonably close to the nominal ground profile. Figure 13(c) demonstrates that the raw data (thin dotted
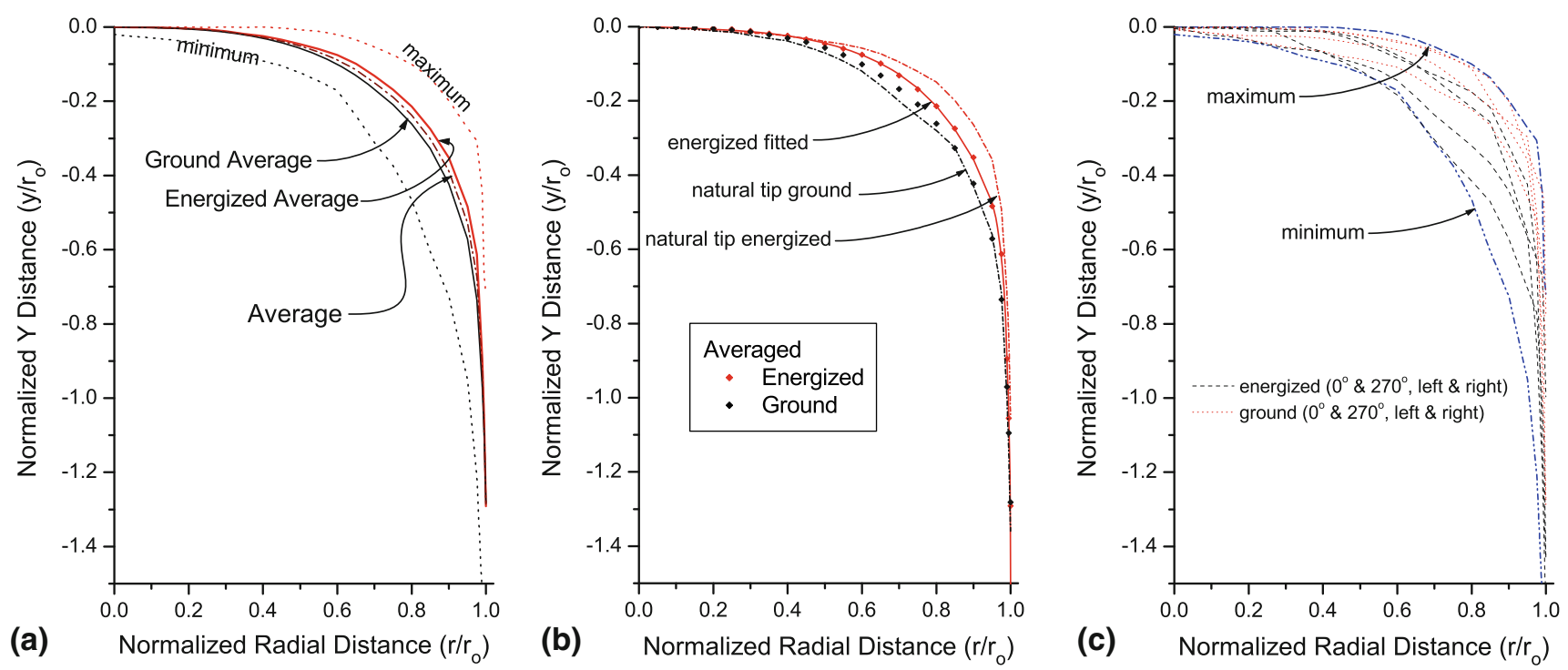

Fig. 13 Electrode tip profiles: (a) average and extremes, (b) the fitted energized electrode (anode) equation, averaged energized and ground (cathode) data, and averaged natural tip (energized and ground) data, and (c) natural tip data (raw and maximum/minimum)

Table 1 Electrode equation best fit parameters to energized electrode tip profile

\begin{tabular}{lccccccc}
\hline $\boldsymbol{y}_{\mathbf{0}}$ & $\boldsymbol{A}_{\mathbf{1}}$ & $\boldsymbol{t}_{\mathbf{1}}$ & $\boldsymbol{A}_{\mathbf{2}}$ & $\boldsymbol{t}_{\mathbf{2}}$ & $\boldsymbol{A}_{\mathbf{3}}$ & $\boldsymbol{t}_{\mathbf{3}}$ & $\boldsymbol{R}^{\mathbf{2}}$ \\
\hline-0.0038865 & 0.59789 & 0.19858 & 0.71285 & 0.01263 & 0.19676 & 0.00065 & 0.99993 \\
\hline
\end{tabular}




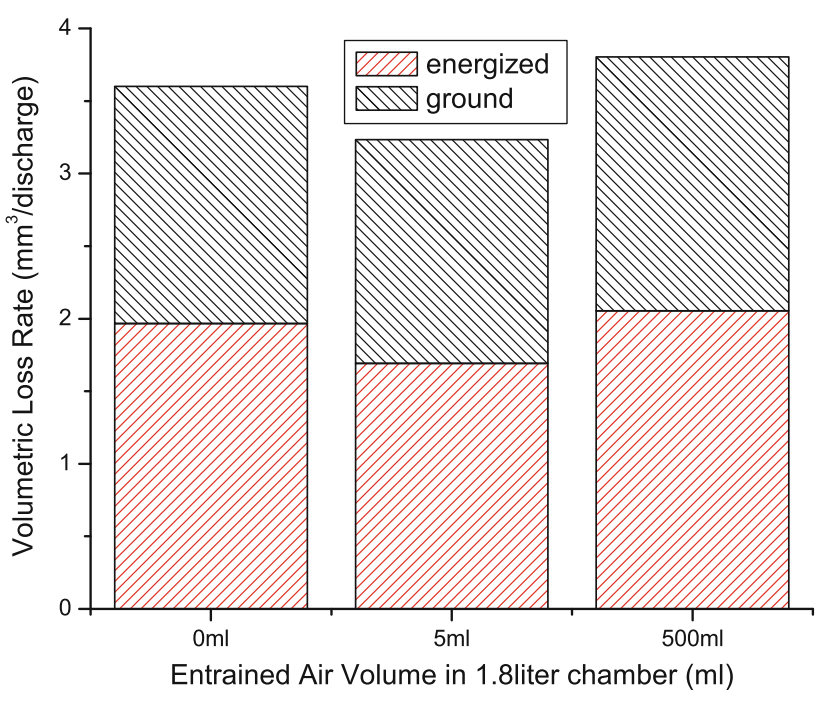

Fig. 14 Effects of entrained air on electrode erosion over 120 discharges in the $1.8 \mathrm{~L}$ chamber

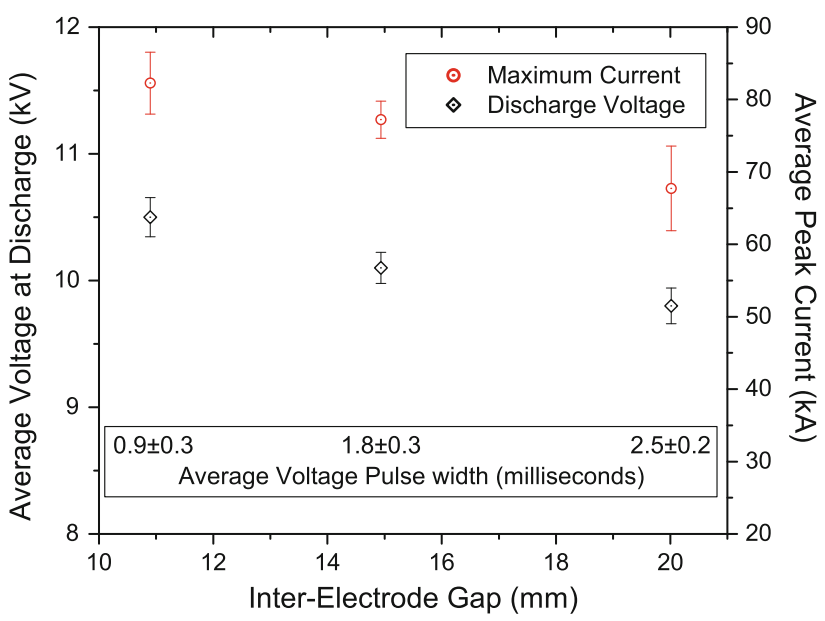

Fig. 15 Electrical response of EHF discharges as a function of inter-electrode gap

and dashed lines) fall almost entirely within the bounds set by the maximum and minimum lines. Thus, the nominal profile tip (as defined by the curve fit) is both geometrically stable as discharges progress and thus maintains reasonably stable electrical performance.

\subsection{Influence of Entrained Air on Electrode Erosion}

A series of erosion tests were carried out using the electrode testing chamber fitted with a special closed volume lid that, because it was closed, maintained a constant level of air at the top of the chamber. The following tests were performed to determine if entrained air in the chamber lowered electrode erosion rates - it was thought that the additional air in the chamber would lower erosion rates. Figure 14 shows the results of tests performed with no air, a small amount of air $(5 \mathrm{~mL})$ and $500 \mathrm{~mL}$ of air in the $1.8 \mathrm{~L}$ electrode testing chamber. Given that the standard deviation in total electrode erosion rate (negative plus positive) combined is around $0.5 \mathrm{~mm}^{3} /$ dis-

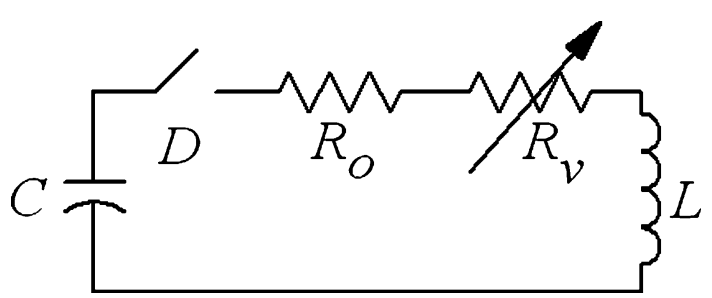

Fig. 16 Electrical circuit model used in EHF ( $C$ - pulse generator capacitance, $L$ - total system inductance, $R_{0}$-resistance of the circuit external to the discharge channel, $R_{\mathrm{v}}$-variable resistance of the discharge channel)

charge, it is fairly clear that there is no substantial effect on erosion of entrained air on erosion rates.

\subsection{The Inter-Electrode Gap and EHF Process Stability}

A study was executed to determine the influence that interelectrode gap has on process stability where ten $11 \mathrm{kV}$ $(12.1 \mathrm{~kJ})$ discharges were performed at each of three different gap settings - all other variables were held constant - and the transient process currents and voltages were measured at the tool. The experimental results showing the average voltage at the moment just before discharge and the peak current during the discharge are shown in Figure 15. Figure 7 shows how these variables were measured. As the gap increases, the average maximum current $\left(I_{\max }\right)$ and the average discharge voltage $\left(V_{\text {discharge }}\right)$ both decrease. With the reductions in peak current and discharge voltage this means that about $10 \%$ of the energy available at process initiation is lost to leak down at the $20 \mathrm{~mm}$ gap setting. As mentioned before, the energy is lost during due to leakage between the exposed electrode surfaces from the moment the voltage is applied to when the plasma channel initiates. This gradual voltage leak down can be observed in Fig. 7 between voltage application and discharge. This voltage loss is due to ionic transport in the working fluid, and, the greater the conductivity of the fluid and the larger the exposed electrode surface area is, the more rapid this loss rate is. The time between voltage application and plasma channel formation is termed the voltage pulse width, and it increases with increasing gap, as is indicated in Fig. 15. The larger the gap, the longer is the voltage pulse width, and the greater is the voltage leak down. However, the $10 \%$ energy loss measured at the $20 \mathrm{~mm}$ gap can be compensated for by a small increase in the operating voltage. Even so, a simple adjustment upwards of $V_{\text {charge }}$ means that EHF system performance can be maintained.

The stability demonstrated in this set of tests indicates that the discharge current and voltage can be measured in a production system and serve as a criterion for adjusting the electrode position as well as serve as a monitor for the health of the system and the quality of the discharge.

\section{Numerical Modeling}

In order to better understand pulse generation and propagation mechanisms in EHF processes, numerical modeling was performed. All stages of the process were modeled starting from the initial discharge channel, where energy deposition starts and leads to the initial shock wave propagation, followed by reflection of pressure waves from the chamber walls until the dynamic pressure dissipates. 


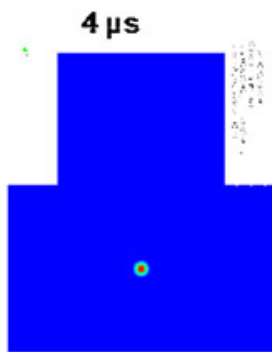

$120 \mu \mathrm{s}$

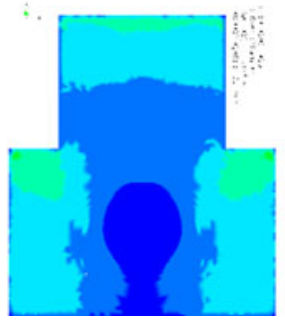

$30 \mu \mathrm{s}$

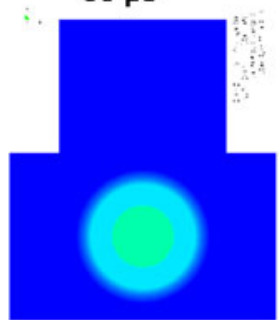

$180 \mu \mathrm{s}$

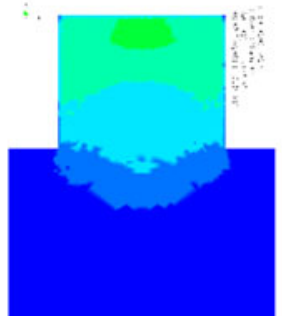

$60 \mu \mathrm{s}$

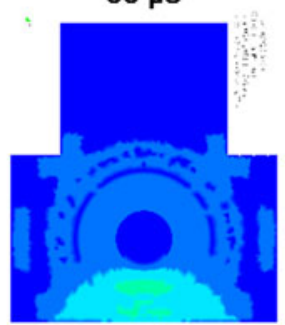

$240 \mu \mathrm{s}$

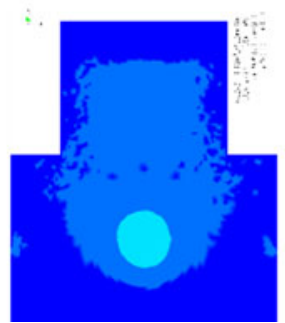

Fig. 17 Distribution of pressure in $\mathrm{kPa}$ versus time in the closed $1.8 \mathrm{~L}$ electrode testing chamber

\subsection{Numerical Simulation of Electrohydraulic Forming}

In order to develop a numerical model of the EHF process, the following models need to be developed and later on coupled: (1) Electrical model of the discharge channel; (2) Model of plasma channel; and (3) Model of the liquid as a pressure transmitting medium. Each individual model was developed using the capabilities of LS DYNA commercial code.

\subsection{Electrical Model of the Discharge Channel}

The model for the current $i(t)$ in the circuit of Fig. 16 includes the variable resistance of the discharge channel $R_{\mathrm{v}}$, the cumulative resistance of the pulsed forming machine and the connecting cables $R_{0}$, and the inductance of the entire discharge circuit $L$. The differential equation for current $i(t)$ in the circuit of Fig. 16 can be written in the following form:

$\frac{d^{2} i}{d t^{2}}+\frac{R_{\mathrm{v}}(i, t)+R_{0}}{L} \cdot \frac{d i}{d t}+\frac{1}{L C} i=0$

The following initial conditions were employed:

$i(0)=0,\left.\quad \frac{d i}{d t}\right|_{t=0}=-\frac{U_{0}}{L}$

where $U_{0}$ is initial voltage of the fully charged capacitor.

The electric power being pumped through the discharge channel can be defined by the following equation:

$N=i^{2}(t) R_{\mathrm{v}}(i, t)$

Integrating Eq. 3 by time produces a function for the energy deposition in the discharge channel $E_{\mathrm{ch}}(t)$ during the discharge process:

$E_{\mathrm{ch}}=\int_{0}^{t} i^{2}(t) R_{\mathrm{v}}(i, t) d t$

\subsection{Plasma Channel}

The plasma channel is modeled in LS DYNA as an adiabatically expanding volume of gas. The electric energy is assumed to be introduced uniformly through the channel volume based upon Eq. 4. The pressure in each finite element of the plasma channel can be calculated as:

$p_{\text {ch }}=(\gamma-1)\left(\rho / \rho_{0}\right) E$

where $p_{\mathrm{ch}}$ is the pressure at a given point of the discharge channel; $\rho$ is the instantaneous spatial mass density; $\rho_{0}$ is the initial spatial mass density; $E$ is the portion of the energy produced within the channel inside a given finite element; and $\gamma$, the adiabatic coefficient for plasma produced from tap water, has a value of $1.26(\operatorname{Ref} 19)$.

\subsection{Model of the Liquid}

The liquid was modeled within LS DYNA as an ideal compressible liquid with a specific cavitation threshold. The list of necessary parameters includes the initial mass density, compression modulus, and negative pressure threshold corresponding to the initiation of cavitation. Heat transfer between the plasma channel and the liquid was not taken into account in this version of the model.

\subsection{Model of the Discharge}

The chamber was modeled as a rigid body by fixing in $x / y / z$ the water boundary nodes. The boundary between plasma and water elements was maintained between the two LaGrangian meshes by means of shared boundary nodes. Results of the combined numerical simulation are shown in Fig. 17. In the initial simulation, the discharge channel was assumed to be a cylindrical tube expanding by the pressure of the plasma, the temperature of which is quickly increasing due to the electric energy deposition during the high-voltage discharge. All the calculations were conducted in a 3D formulation, and the results are shown at the central cross section. The discharge 
channel was meshed with an FEM mesh in order to control its shape progression. The most difficult area from a simulation point of view is where three different media of different physical nature are in contact interaction. Such an area is at the boundary of the plasma channel, the liquid filling the chamber, and one of the electrodes. Since the shape of the plasma channel becomes spherical almost at the beginning of the process, the decision was made to consider it spherical from the very beginning of the EHF process, which eliminates the issue of simulating the contact interaction of three different media.

\subsection{Numerical Simulation Results}

Figure 17 shows the development of the pressure distribution within the electrode testing chamber: at $4 \mu$ s the high pressure region is confined to the space between the electrodes. At $30 \mu \mathrm{s}$, the moment of peak current transfer and the moment where $90 \%$ of the energy has been delivered into the plasma channel, the pressure wave has taken spherical geometry and it maintains this geometry until the pressure wave begins to interact with the walls. At $60 \mu \mathrm{s}$ the pressure wave has struck and rebounded from the bottom of the chamber, creating a high pressure zone below the electrodes, and the rest of the initial pressure wave continues to propagate spherically. At $120 \mu$ s the spherical coherence of the original wave has been lost and the rebounding waves constructively and destructively interact to form high pressure zones in the sides and top of the chamber. After $180 \mu \mathrm{s}$ the bulk of the high pressure resides in the top of the chamber. Lastly, after $240 \mu \mathrm{s}$, the last of the current has passed through the system and the plasma channel has collapsed.

From this simulation it is believed that, since the bulk of the energy and pressure resides between the electrode tips during the early portion $(<30 \mu \mathrm{s})$ of the discharge, the bulk of the electrode erosion and damage also occurs during this period. As is evident from the simulation, peak pressures occur within this time window and, outside of it, the subsequent pressures are far lower in the region around the electrode tips.

\section{Discussion}

The development of a stable, robust electrode system depends critically on the electrode rod material withstanding the energies, forces, shock wave pressures, and erosive plasma within the EHF chamber. Further, the electrode system needs to be electrically stable to be able to deliver a consistent and known amount of energy to the blank with each pulse in order to reliably and fully form sheet metal panels.

Of the materials examined in this work, steel appears to have the best combination of erosion properties and structural performance - the only material to survive a full 120 discharges in the electrode testing chamber and the one with the lowest erosion rate. Tungsten and molybdenum have very high material and manufacturing costs, and the erosion rates would have to be significantly lower than steel to make them economically feasible. Donaldson et al.'s (Ref 12) work in air (rather than water) suggests that further investigation with the copper-tungsten PM alloy or a stainless steel might be worthwhile, and that a hybrid steel electrode might overcome some of the durability issues that were observed with the alternate materials (Ref 16). Donaldson and coworkers work (Ref 12) indicating that volume lost in each discharge in air was constant was found to be true of electrohydraulic discharges as well, and the average combined (positive and negative) loss rate for the low carbon steel used here was $3.7 \mathrm{~mm}^{3} /$ discharge (across all relevant experiments) while the molybdenum was double at $7.6 \mathrm{~mm}^{3} /$ discharge. From available evidence it is clear that erosion will have to be accommodated into the system design rather than eliminated through materials selection.

Further, it was determined that steel, the material selected for further study, simply could not hold its tip shape under multiple discharges - the original shape eroded away after roughly 50 discharges regardless of the initial shape - and an evolving tip shape poses problems to the electrical stability of the discharge over the life of the electrode. Thus, it was decided that, rather than optimizing the electrodes for electrical efficiency, starting out with the average as-eroded tip profile was critical. This "natural" profile was determined, tested and found to be geometrically stable. Since the erosion needs to be accommodated in the system design, the electrical stability as a function of inter-electrode gap was demonstrated to be reasonably stable out to $20 \mathrm{~mm}$. This configuration appears to be appropriate for a production system employing an adjustable electrode insertion mechanism capable of advancing the electrodes to maintain the gap (Ref 16).

Numerical modeling indicated that the highest pressures near the electrode tips were found within the first $30 \mu \mathrm{s}$ following plasma channel formation, and that the first pressure wave did not reach the chamber wall until after roughly $60 \mu$ s. Subsequently, only lower pressures were observed around the electrode tips. Thus, it is not surprising that the performance of the electrodes with entrained air demonstrated no appreciable change in erosion rate over no air because it appears that the damage mechanisms operate within that initial $30 \mu$ s window. It is expected that most electrode erosion arises from the plasma and the high initial pressures.

In order to build an economical electrohydraulic forming production system, the electrode system should not require maintenance any more often than once per work shift, less often if possible. So, an estimate of the number of pulses in a single production shift is necessary. From previous work on process timing, a panel can be formed by this process every $36 \mathrm{~s}$. Assuming that each panel requires 5 pulses, an $8 \mathrm{~h}$ shift and constant operation, 4,000 pulses will be applied to the electrodes before replacement.

In order to determine the full durability life, a set of steel electrodes was tested to failure in the $1.8 \mathrm{~L}$ electrode testing chamber. Once again $11 \mathrm{kV}$ pulses were applied, and the electrodes were inspected every 100 discharges and advanced to correct the gap if necessary. In the end $200011 \mathrm{kV}$ discharges were placed upon the electrodes before they became unusable. This result indicates that the electrodes would last roughly half of a production shift and require replacement. Again, because the numerical modeling suggests that the primary damage comes from the first $30 \mu \mathrm{s}$ and before the pressure wave has had a chance to interact with the chamber wall, it is not expected that the chamber volume will have much impact on the volumetric erosion rate.

\section{Conclusions}

A series of tests on electrodes were conducted to study the viability of EHF for production applications. The electrode 
system was studied because it is subject to the largest forces/ stresses of any component within the EHF system. The study investigated material, tip shape, chamber volume, the role of entrained air in the chamber, and the electrical stability of the discharges as a function of gap, and a numeric model of the process was developed. It was determined that:

1. Steel was the best material of the four tested with an erosion rate of $3.7 \mathrm{~mm}^{3} /$ discharge. The molybdenum had an erosion rate of $7.6 \mathrm{~mm}^{3} /$ discharge, and neither the $\mathrm{Mo}$, tungsten or the tungsten-copper alloy was able to withstand the stresses caused by the discharge.

2. It was determined that none of the initial tip shapes was sufficiently geometrically stable under erosion as every initial tip shape was eliminated once roughly 50 discharges were applied. Thus the naturally eroded tip geometry was determined from as-eroded electrodes, tested, and found to be geometrically stable.

3. The electrohydraulic erosion rate of steel was found to be constant regardless of tip design for $11 \mathrm{kV}$ discharges in the $1.8 \mathrm{~L}$ chamber.

4. Entrained air in the chamber had no influence on erosion rates but numeric modeling suggested that most of the damage occurs before the pressure wave has had a chance to interact with the chamber walls or air, and that chamber volume was unlikely to have an effect on rates.

5. It was predicted that a steel conductor electrode system would likely require a single change during an $8 \mathrm{~h}$ production shift but would survive 2000 discharges.

\section{Acknowledgments}

This material is based upon work supported by the Industrial Technology Program of the US Department of Energy under Award Number DE-FG36-08GO18128. Additionally, the authors would like to acknowledge Raymond Silva who made valuable contributions in electrode fabrication technique and overall experimental work.

\section{Disclaimer}

This report is prepared as an account of work sponsored by an agency of the United States Government. Neither the United States Government nor any agency thereof, nor any of their employees, makes any warrantee, express or implied any legal liability or responsibility for the accuracy, completeness, or usefulness of any information, apparatus, product, or process disclosed, or represents that its use wouldn't infringe any privately owned rights. Reference herein to any specific commercial product, process or service by trade name, trademark, manufacturer, or otherwise does not necessarily constitute or imply its endorsement or recommendation or favouring by the United States Government or any agency thereof. The views and opinions of authors expressed herein do not necessarily state or reflect those of the United States Government or any agency thereof.

\section{References}

1. V.S. Balanethiram and G.S. Daehn, Hyperplasticity: Increased Forming Limits At High Workpiece Velocity, Scr. Metallurgica et Materialia, 1994, 31, p 515-520

2. S.F. Golovashchenko, Material Formability and Coil Design in Electromagnetic Forming, J. Mater. Eng. Perform., 2007, 16(3), p 314-320

3. L.A. Yutkin, Electrohydraulic Effect, Mashgiz (State Scientific Technical Press for Machine Construction Literature), Translation No. AD267-722. Armed Services Technical Information Agency, Arlington Hall Station, Arlington, 1955

4. E.J. Bruno, High-Velocity Forming of Metals, American Society of Tool and Manufacturing Engineers, Dearborn, 1968

5. R. Davies and E.R. Austin, Development in High Speed Metal Forming, Industrial Press Inc., New York, 1970

6. S.F. Golovashchenko and V.S. Mamutov, Electrohydraulic Forming of Automotive Panels, Proceedings of the 6th Global Innovations Symposium: Trends in Materials and Manufacturing Technologies for Transportation Industries, T.R. Bieler, J.E. Carsley, H.L. Fraser, J.W. Sears, and J.E. Smugeresky, Eds., 2005, (San Francisco), TMS, p 6570

7. V.J. Vohnout, G. Fenton, and G.S. Daehn, Pressure Heterogeneity in Small Displacement Electrohydraulic Forming Process, Proceedings of 4th International Conference on High Speed Forming, G. Daehn, Ed., 2010 (Columbus), IUL, 2010, p 65-74

8. S.F. Golovashchenko, A.V. Mamutov, J.J.F. Bonnen, and A.J. Gillard, Electrohydraulic Forming Of Sheet Metal Parts, Proceedings of the International Conference on Technology of Plasticity, G. Hirt and A.E. Tekkaya, Eds., 2011 (Aachen Germany), RWTH Aachen and IUL, 2011, p 1170-1175

9. J.J.F., Bonnen, S.F. Golovashchenko, S.A. Dawson, A. Mamutov and A.J. Gillard, Electrohydraulic Sheet Metal Forming of Aluminum Panels, Proceedings of the TMS Light Metals 2012 Conference, C.E. Suarez, Ed., 2012 (Orlando), TMS, 2012, p 449-454

10. A.M. Loske and F.E. Prieto, The Influence of Electrode Shape on the Performance of Electrohydraulic Lithotripters, J. Stone Dis., 1993, 5(4), p 228-239

11. Š. Potocký, N. Saito, and O. Takai, Needle Electrode Erosion in Water Plasma Discharge, Thin Solid Films, 2009, 518, p 918-923

12. A.L. Donaldson, M.O. Hagler, M. Kristiansen, G. Jackson, and L. Hatfield, Electrode Erosion Phenomena in a High-Energy Pulsed Discharge, IEEE Trans. Plasma Sci., 1984, PS-12(1), p 28-38

13. A.L. Donaldson, M. Kristiansen, A. Watson, K. Zinsmeyer, and E. Kristiansen, Electrode Erosion in High Current, High Energy Transient Arcs, IEEE Trans. Magn., 1986, MAG-22(6), p 1441-1447

14. S.F. Golovashchenko, A.J. Gillard, D. Piccard and A.M. Ilinich, Electrohydraulic Forming Tool and Method of Forming Sheet Metal Blank with the Same, US Patent 7,802,457, 28 Sep 2010

15. V.N. Chachin, Electrohydraulic Treatment of Materials, Science and Engineering, Minsk, 1978, p 183. (in Russian)

16. J.J.F. Bonnen, S.F. Golovashchenko, and S.A. Dawson, Electrode Assembly for Electro-Hydraulic Forming Process, US Patent Application Publication 2012/0111080 A1, 10 May 2012, p 12

17. N.A. Kostin, V.S. Kublanovskiy, V.A.Zabludovskiy, Pulsed Electrolyzation. 1989 (Kiev), Naukova Dumka, p 168. (in Russian)

18. V.M. Kosenkov and N.I. Kuskova, Development of Breakdown in Water, Sov. Phys. Tech Phys., 1987, 32(10), p 1215-1217

19. K.A. Naugolnyh, N.A. Roy, Electrical Discharges in Water, Nauka, Moscow, 1971, p 155. (in Russian) 